\title{
Using information theory to determine optimum pixel size and shape for ecological studies: Aggregating land surface characteristics in arctic ecosystems
}

\section{Authors: Paul C. Stoy, M. Williams, L. Spadavecchia, R. A. Bell, A. Prieto-Blanco, J. G. Evans, and M. T. van Wijk}

The final publication is available at Springer via https://dx.doi.org/10.1007/s10021-009-9243-7.

Stoy, P. C., M. Williams, L. Spadavecchia, R. A. Bell, A. Prieto-Blanco, J. G. Evans, and M. T. van Wijk. "Using Information Theory to Determine Optimum Pixel Size and Shape for Ecological Studies: Aggregating Land Surface Characteristics in Arctic Ecosystems." Ecosystems 12, no. 4 (March 10, 2009): 574-589. doi:10.1007/s10021-009-9243-7. 


\title{
Using Information Theory to Determine Optimum Pixel Size and Shape for Ecological Studies: Aggregating Land Surface Characteristics in Arctic Ecosystems
}

\author{
P. C. Stoy, ${ }^{1 *}$ M. Williams, ${ }^{1,2}$ L. Spadavecchia,${ }^{1,2}$ R. A. Bell, ${ }^{1,3}$ \\ A. Prieto-Blanco, ${ }^{4}$ J. G. Evans, ${ }^{5}$ and M. T. van Wijk ${ }^{6}$
}

\begin{abstract}
${ }^{1}$ School of GeoSciences, University of Edinburgh, Edinburgh EH9 3JN, UK; ${ }^{2}$ NERC Centre for Terrestrial Carbon Dynamics, University of Edinburgh, Edinburgh, UK; ${ }^{3}$ Centre for Ecology, Evolution and Conservation, University of East Anglia, Norwich, UK; ${ }^{4}$ Department of Geography, University College London, 26 Bedford Way, WC1H 0AP London, UK; ${ }^{5}$ Centre for Ecology and Hydrology, Maclean Building, Benson Lane, Crowmarsh Gifford, Wallingford, Oxfordshire OX10 8BB, UK; ${ }^{6}$ Plant Production Systems, Wageningen
\end{abstract} University, P.O. Box 430, 6700 AK Wageningen, The Netherlands

\begin{abstract}
Quantifying vegetation structure and function is critical for modeling ecological processes, and an emerging challenge is to apply models at multiple spatial scales. Land surface heterogeneity is commonly characterized using rectangular pixels, whose length scale reflects that of remote sensing measurements or ecological models rather than the spatial scales at which vegetation structure and function varies. We investigated the 'optimum' pixel size and shape for averaging leaf area index (LAI) measurements in relatively large $\left(85 \mathrm{~m}^{2}\right.$ estimates on a $600 \times 600-\mathrm{m}^{2}$ grid) and small $\left(0.04 \mathrm{~m}^{2}\right.$ measurements on a $40 \times 40-\mathrm{m}^{2}$ grid) patches of sub-Arctic tundra near Abisko, Sweden. We define the optimum spatial averaging operator as that which preserves the information content
\end{abstract}

(IC) of measured LAI, as quantified by the normalized Shannon entropy $\left(E_{\mathrm{S}, \mathrm{n}}\right)$ and KullbackLeibler divergence $\left(D_{\mathrm{KL}}\right)$, with the minimum number of pixels. Based on our criterion, networks of Voronoi polygons created from triangulated irregular networks conditioned on hydrologic and topographic indices are often superior to rectangular shapes for averaging LAI at some, frequently larger, spatial scales. In order to demonstrate the importance of information preservation when upscaling, we apply a simple, validated ecosystem carbon flux model at the landscape level before and after spatial averaging of land surface characteristics. Aggregation errors are minimal due to the approximately linear relationship between flux and LAI, but large errors of approximately $45 \%$ accrue if the normalized difference vegetation index (NDVI) is averaged without preserving IC before conversion to LAI due to the nonlinear NDVI-LAI transfer function.

Key words: information content; Kullback-Liebler divergence; leaf area index; Shannon entropy; spatial averaging; triangulated irregular network; tundra; upscaling. 


\section{INTRODUCTION}

Process-based models of ecological function are usually parameterized using measurements at a particular plot or suite of plots, which sample only a small fraction of the landscape. This limited sampling means that it is difficult to parameterize ecosystem models across space, which hinders our ability to accurately estimate multi-scale ecosystem function. General approaches to this 'upscaling' problem remain elusive, but often focus on describing mechanistic linkages among leaves, plants, ecosystems, and landscapes (Jarvis and McNaughton 1986; Leuning and others 1995; Williams and others 2001), with careful consideration of spatial aggregation and the errors that it may incur (O'Neill and Rust 1979; Rastetter and others 1992; Pelgrum 2000).

Although the global carbon (C) budget is well constrained (Canadell and others 2007), and intensively measured plots are understood in great detail (Baldocchi 2008), the intermediate landscape scale remains poorly quantified. Both 'top-down' (Gurney and others 2004) and 'bottom-up' (Potter and others 2006) approaches have been used to scale from global and local data, but neither have been completely successful nor consistent. Addressing the question of scale is central for bridging the gap between bottom-up estimates of ecosystem function and top-down estimates from global earth system models (GCMs, DGVMs) that are becoming increasingly explicit in their representation of the land surface (Essery and others 2003), but require statistical downscaling for regional extrapolation (Wilby and Wigley 1997). Coping with the natural heterogeneity of landscape structure and process remains a critical limitation to scaling efforts.

A common approach to upscaling across space in physiological and ecosystem ecology is to break the land surface into pixels that are typically square, and to represent ecological processes at this pixel scale. Some studies have sought to implement pixels as the central unit that describes ecological [for example 'PROXEL,' Tenhunen and others (1999)] and/or hydrological processes (Mauser and others 2001), and use these process-based pixel models as the basis for scaling up. But pixel size is often selected arbitrarily or seemingly imposed by the resolution of remote sensing platforms (for example, 250-1000 m for the Moderate-Resolution Imaging Spectroradiometer, MODIS) and the pixels may not have the optimal grain size to adequately capture the dominant topographic and vegetative features of the landscape. For example, Rahman and others (2003) performed a semivariogram analysis to determine that pixel sizes of $6 \mathrm{~m}$ or less are preferred for hyperspectral studies of California chaparral ecosystems given spatial variability in vegetation, yet most attempts at aggregation use a larger grain size. Heinsch and others (2006) demonstrated errors in productivity estimates when the spatial scale of plots measured by eddy covariance is smaller than the $1 \times 1 \mathrm{~km}^{2}$ grain of MODIS pixels. Few ecological studies have investigated the importance of pixel size and shape for upscaling local measurements to larger spatial scales (but see Rahman and others 2003), despite efforts from the DGVM and GCM communities to test the importance of both grid size (Müller and Lucht 2007) and shape (Walko and Avissar 2006) in their simulations.

Similarly, few if any examples of upscaling in ecology consider the loss or change in information inherent in aggregation across spatial scales, its consequences, or potential solutions, despite the widespread use of information-theoretic approaches in ecological modeling (Ulanowicz 2001; Burnham and Anderson 2002). Changes in information content (IC) depend of course on how information is quantified, but always involve the distribution of the variable of interest as expressed through the numerical or analytical probability distribution (or density) function (Shannon 1948; Kullback 1997). Techniques from information theory have been applied to quantify how much information is gained or lost upon increasing or decreasing the spatial grain of observations from remote sensing platforms (Chen and Blong 2002), but rarely for upscaling ecosystem function (Brunsell and Young 2007; Brunsell and others 2008). We propose that metrics for quantifying IC can be used to select preferential upscaling techniques to minimize information loss or alteration when changing spatial grain and to avoid aggregation errors due to potential nonlinearities in the upscaling procedure (Pelgrum 2000).

Here, we investigate approaches from information theory for quantifying optimum pixel sizes and shapes for process-based ecological studies, focusing on the spatial averaging of normalized difference vegetation index (NDVI) measurements and associated leaf area index (LAI) estimates in an Arctic tundra ecosystem. By 'optimum,' we suggest that a spatial averaging operator should: (1) preserve the IC of a key measured ecosystem attribute, in this case LAI, and (2) minimize the number of pixels (maximize pixel size) for efficient computation across time and space, for example, in conjunction with landscape-level data assimilation techniques (Williams and others 2005; Quaife and 
others 2008). Thus, our definition of optimum takes a practical rather than strict mathematical view. Specifically, we ask the question: how does the spatial averaging operator alter the probability distribution function (pdf) of LAI (hereafter $p(\mathrm{LAI})$ ) measured at finer scales in sub-Arctic tundra ecosystems, and can we find an averaging operator with a minimum number of pixels that retains the fine-scale IC of LAI?

LAI averaging is investigated because of its general importance in describing plant structure and function (Monteith and Unsworth 1990), and because of its particular importance in the sub-Arctic tundra ecosystems that we investigate here. LAI is strongly related to nutrient distribution such as bulk canopy nitrogen (N) in tundra ecosystems (Williams and Rastetter 1999; van Wijk and others 2005), which are in turn coupled more strongly to short-term productivity than C supply, air temperature, or vegetation life-form (Shaver and others 1986, 1992, 2007). Consequently, there is a strong relationship between LAI and gross primary productivity (GPP) in Arctic tundra, regardless of species (Street and others 2007). LAI plays a central role in creating patterns of $\mathrm{C}$ uptake and nutrient distribution across space across Arctic ecosystems, and its spatial distribution must be accurately characterized in a simple way for spatial modeling.

LAI may have a linear relationship with some Arctic ecosystem processes, such as GPP, over part of its range (Street and others 2007). In this case, only an accurate estimate of mean landscape-level LAI is required to obtain an unbiased estimate of spatially averaged GPP. However, nonlinear relationships exist between LAI and the surface radiation balance (Kustas and Norman 2000), and thus soil temperature and hydrology. Any alteration of $p$ (LAI) is likely to result in inaccurate or biased upscaled averages or sums of these quantities (Rastetter and others 1992). Similarly, spatial averaging of meteorological, hydrological, edaphic, or earth observation (EO)-based model inputs may incur errors if the model transfer function is nonlinear (Pelgrum 2000). For example, the transfer function between remotely sensed NDVI and LAI in Arctic tundra is highly nonlinear (van Wijk and Williams 2005; Williams and others 2008), and thus prone to averaging errors which we demonstrate in a C cycle modeling example. These issues are referred to as the subgrid scaling problem (Entekhabi and Eagleson 1989; Kustas and Norman 2000), and we seek to address this problem in part using techniques from information theory.

The central premise of our approach is that the fine-scale IC can and should be preserved to obtain an 'upscaled' landscape that shares similar probabilistic features of the land surface at finer scales (Figure 1). Spatial averaging may incur some alteration of IC due solely to the central limit theorem: if each pixel contains a random distribution of LAI values, $p$ (LAI) will approach a Gaussian (normal) distribution upon averaging (Figure 1). However, vegetation need not be distributed randomly, particularly in tundra ecosystems where plant distribution is often clumped (Bliss 1962; Spadavecchia and others 2008). We can take advantage of these non-random landscape features in our spatial averaging approach if topographic features that are related to ecosystem hydrology, insolation, or exposure are statistically related to LAI (Spadavecchia and others 2008), noting the coupling between microtopography and $\mathrm{C}$ cycle function in Arctic ecosystems (Sullivan and others 2008). Accounting for coupled LAI-microtopographical variation may represent an improvement over simple grid-based averaging given our criteria for selecting an optimal averaging operator.

Remotely sensed data generally represent average reflected radiant flux per unit ground area (per solid angle of the sensor), convolved with the instrument point-spread function over a square or rectangular pixel. The field of view is often elliptical, and consequently the square or rectangular output is the result of some subsampling and averaging. Despite the tendency for remote sensing products to deliver rectangular pixels, some examples from the hydrological literature have demonstrated the usefulness of other shapes for spatially explicit modeling. Namely, triangular irregular networks (TINs) (Kumler 1994; Ivanov and others 2004; Vivoni and others 2004, 2005b) are explored as a means to generate Voronoi polygons for spatial averaging, and we investigate if TINs present advantages for spatial averaging over regular grid-based averaging schemes. TINs can be generated efficiently (Goodrich and others 1991) and, along with the Delaunay triangulation that forms their basis, are supported in common software packages such as ArcGIS (ERSI, Redlands, CA) and MATLAB (MathWorks, Natick, MA). TINs can also be implemented without the subjectivity imposed by user parameterization. We envision that TINs can provide a connection among studies on ecosystem structure, computational hydrology, and other effects of topography [for example, radiation distribution or topographic exposure (TOPEX)] on controlling vegetation distribution and function, and thus present a formal method for efficiently co-classifying and upscaling multiple processes from the plot to the landscape scale. 

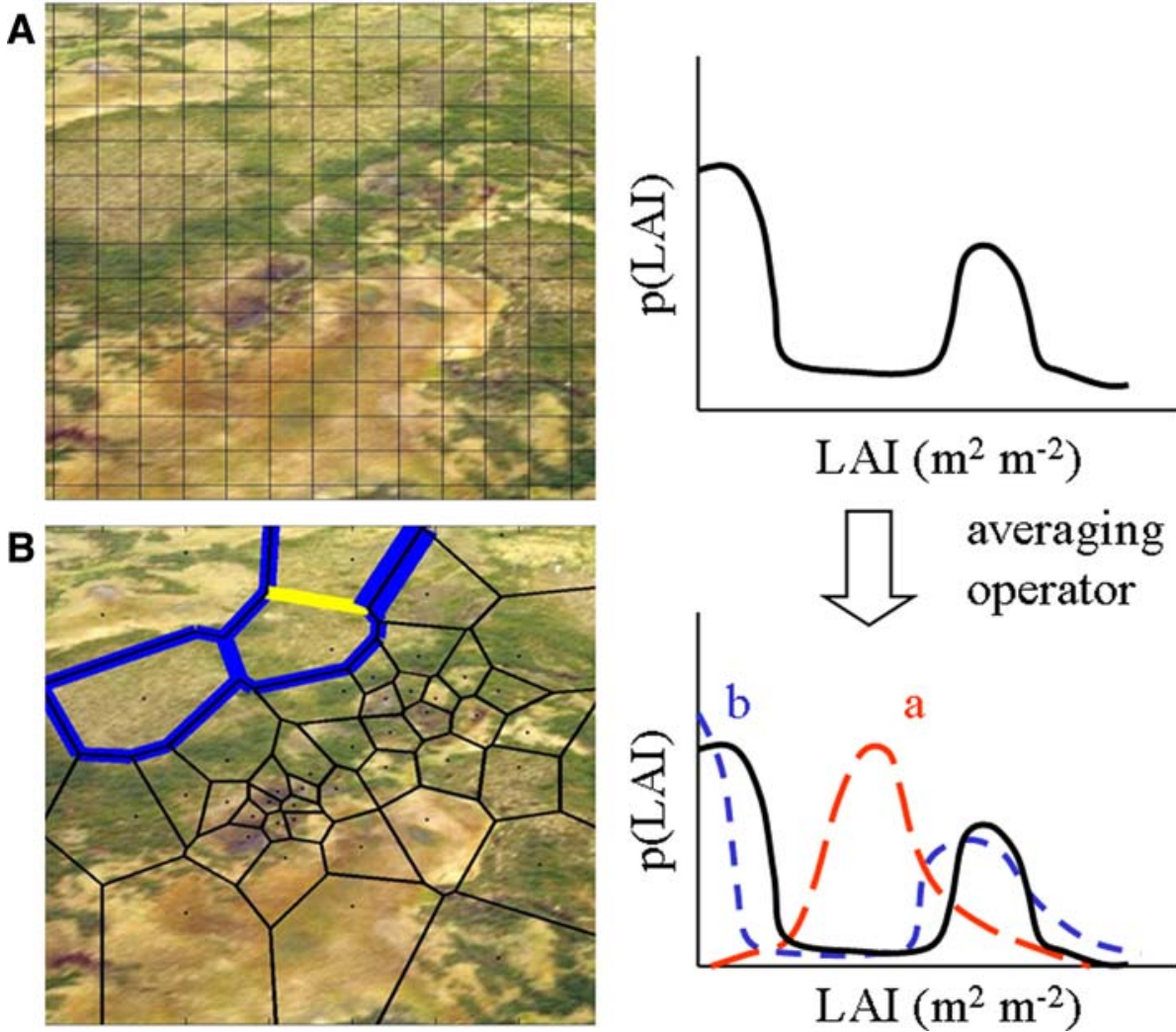

Figure 1. A conceptual example of the effect of spatial averaging operators, in this case (A) squares and (B) Voronoi polygons created from a TIN, on altering the probability distribution, and thus IC, of LAI in a sub-Arctic tundra landscape. The right-hand graphs represent a conceptual probability distribution of LAI (top) and how it may be modified by spatial averaging (bottom). It is envisioned that certain sizes and/or shapes will retain the IC of fine-scale LAI measurements in a way that also maximizes average pixel size. A properly conditioned TIN may also be useful for quantifying the effective length and volume of the edge between different vegetative types as indicated by the blue lines. Polygons may be combined by removing unnecessary edges as demonstrated with the yellow line. Source: Image courtesy of Mathew Williams.

We argue that there is a quantifiable optimum pixel size and shape that can be determined by exploring the IC of spatially averaged land surface features. Specifically, we hypothesize that, given the importance of topography in controlling plant distribution in Arctic landscapes (Walker and others 1995) and for the arrangement of LAI and surface topography in our study area, TINs based on hydrologic similarity will be superior averaging operators than simple grids (Hypothesis 1). In this sense, rectangular averaging operators represent a null hypothesis. Furthermore, TINs conditioned upon topographic features related to statistical clumping of LAI for our study ecosystems (Spadavecchia and others 2008), namely TOPEX at small spatial scales, will be superior to those based on hydrologic similarity alone (Hypothesis 2). We investigate the spatial averaging of LAI at two canonical scales in sub-Arctic tundra: the sub-meter or 'micro-scale' using intensively sampled data from van Wijk and Williams (2005), and the scale of tens-of-meters ('macro-scale') based on extending the findings of van Wijk and Williams (2005) to a larger area (Williams and others 2008). We then use insight from the averaging exercises to illustrate an 'optimum' TIN that couples hydrologic and vegetative similarity at the macro-scale, and use this aggregation procedure to demonstrate the importance of information preservation for upscaling ecological function using a validated ecosystem C flux model (Shaver and others 2007) driven by meteorological measurements made near the study site.

\section{Methods}

\section{Study Sites}

Changes in IC incurred by the spatial averaging of LAI are explored using two published datasets of LAI distribution from a tundra ecosystem near Abisko, Sweden $(410,130 \mathrm{~m}$ east, 7,583,892 m north, UTM zone $34 \mathrm{~W}$ ). Long-term average 
rainfall at Abisko is $400 \mathrm{~mm} \mathrm{y}^{-1}$ and the average temperature is $-1^{\circ} \mathrm{C}$ (Christensen and others 2004). The study domain comprises a gentle $5^{\circ}$ downward slope from SW to NE. Topographical variations also occur at higher spatial frequency in heath-dominated patches, with mound/pit structures at a spatial scale of several meters (van Wijk and Williams 2005; Spadavecchia and others 2008; Williams and others 2008). Vegetation at the study site is dominated by a low heath characterized by Empetrum nigrum L. Betula nana L. often grows in sheltered dips (van Wijk and Williams 2005). Some wooded areas are also present as the macro-scale dataset lies close to the transition zone from tundra to birch woodland. These woodland areas are characterized by Betula pubescens ssp. tortuosa (Ledeb.) Nyman with an understory that is commonly comprised of Vaccinium species including $V$. myrtillus L., V. uliginosum L., and V. vitis-idaea L. Wooded areas are excluded from the example of $\mathrm{C}$ flux modeling, as the model was parameterized for pan-Arctic tundra ecosystems. A stream running through the center of the study area is bordered by shrubby riparian vegetation characterized by B. nana and Salix spp. Soils are rocky and well drained (Jonasson and others 1999).

\section{LAI Measurements}

The 'macro-scale' dataset (Williams and others 2008) includes 228 NDVI measurements (Skye Instruments 2 Channel Sensor SKR1800, Skye Instruments, Llandrindod Wells, UK) of $85 \mathrm{~m}^{2}$ plots that were converted into LAI estimates using the methods described in the study of van Wijk and Williams (2005). Briefly, van Wijk and Williams (2005) combined 5625 LAI-2000 (LI-COR, Lincoln, NE, USA) and Skye SKR 1800 NDVI measurements with direct LAI measurements from 81 destructive harvests to create a LAI map of the micro-scale study area at the scale of $0.2 \times 0.2 \mathrm{~m}^{2}$. The 'microscale' dataset (van Wijk and Williams 2005) includes LAI estimates from these 5625 paired LAI and NDVI measurements. The study domain was nearly $600 \times 600 \mathrm{~m}^{2}$, which encompasses the $40 \times 40 \mathrm{~m}^{2}$ domain of the micro-scale dataset (Spadavecchia and others 2008; Williams and others 2008). Both sets of measurements were taken during the peak growing season at Abisko.

\section{Methods: IC}

Three metrics are employed to quantify the alteration in IC incurred by spatial averaging: the normalized Shannon entropy $\left(E_{\mathrm{S}, \mathrm{n}}\right)$ (Shannon
1948; Wesson and others 2003) and the numerical and analytical Kullback-Leibler divergence $\left(D_{\mathrm{KL}}\right)$ (Kullback and Leibler 1951; Kullback 1997).

The $E_{\mathrm{S}, \mathrm{n}}$ is simply the absolute value of the Shannon entropy divided by the log of the number of histogram bins $(N)$ into which the distribution is divided such that potential values are bounded between 0 and 1 .

$$
E_{\mathrm{S}, \mathrm{n}}=\left|\frac{\sum_{i=1}^{N} p(i) \ln p(i)}{\ln (N)}\right|,
$$

where $p(i)$ is the discrete probability distribution of any variable $x$, here LAI or NDVI. The $E_{\mathrm{S}, \mathrm{n}}$ takes a maximum value of 1 for a uniform distribution, and a minimum of 0 for a Dirac delta function (Katul and others 2001; Stoy and others 2006). pdfs of different size and shape may have the same $E_{\mathrm{S}, \mathrm{n}}$ for example, two identically shaped distributions with different ranges. In order to avoid this limitation, we scaled the bins' locations between 0 and the maximum measured LAI for the micro- and macro-scale datasets, respectively.

The $D_{\mathrm{KL}}$ (also called the Kullback-Leibler difference, information divergence or gain, or relative entropy) quantifies the difference between two arbitrary pdfs $q$ and $m$ :

$$
D_{\mathrm{KL}}=\sum_{i=1}^{N} q(i) \ln \frac{q(i)}{m(i)}
$$

where, in our case, $q$ represents the probability density function of the LAI measurements at either the micro-scale or macro-scale and $m$ is the resultant pdf of LAI after spatial averaging (Kullback and Leibler 1951; Kullback 1997).

$N$ of 10 bins was chosen for both the $E_{\mathrm{S}, \mathrm{n}}$ and $D_{\mathrm{KL}}$ as the length of the data series becomes small when the size of the spatial averaging operators become large. Results may be sensitive to $N$. In order to avoid these limitations, analytical expressions that do not require binning can be employed. A logical choice for modeling $p$ (LAI) is the gamma distribution as LAI is a continuous variable bounded by zero. The $D_{\mathrm{KL}}$ for the gamma distribution $\left(\Gamma D_{\mathrm{KL}}\right)$ can be quantified using

$$
\Gamma D_{\mathrm{KL}}=\log \left(\frac{\Gamma\left(\alpha_{0}\right) \beta_{0}^{\alpha_{0}}}{\Gamma(\alpha) \beta_{0}^{\alpha_{0}}}\right)+\left(\alpha-\alpha_{0}\right) \psi(\alpha)+\alpha \frac{\beta-\beta_{0}}{\beta_{0}},
$$

where $\alpha$ and $\beta$ are the shape and scale parameters of the gamma distribution determined using maximum-likelihood estimation, $\Gamma(\alpha)$ is the gamma function for $\alpha$, and $\psi(\alpha)$ is the digamma function for $\alpha$ (Mathiassen and others 2002). 
Similarly, NDVI is constrained between 0 and 1 , and a logical choice for modeling its pdf is the beta distribution, for which the $D_{\mathrm{KL}}$ is:

$$
\begin{aligned}
B D_{\mathrm{KL}}= & \log \left(\frac{B(\eta, \rho)}{B\left(\eta_{0}, \rho_{0}\right)}\right)-\left(\eta-\eta_{0}\right) \psi\left(\eta_{0}\right) \\
& -\left(\rho-\rho_{0}\right) \psi\left(\rho_{0}\right)+\left(\eta-\eta_{0}+\rho-\rho_{0}\right) \psi\left(\eta_{0}+\rho_{0}\right)
\end{aligned}
$$

where $B(\eta, \rho)$ is the incomplete beta function for the beta shape parameters $\eta$ and $\rho$.

\section{Rectangular Averaging Operators}

We first consider simple grids as spatial averaging operators, beginning with squares oriented in the ordinal directions, then rotated $45^{\circ}$ to test if grid cell orientation has a discernable impact on IC after spatial aggregation. We then explore 3:1 rectangles oriented both north-south and east-west, as well as $45^{\circ}$ rotated versions of these rectangles to test whether spatial averaging with respect to topographical features, namely the direction of the slope, which runs SE to NW, can result in an improved spatial averaging operator based on our criteria. These results demonstrate that topographic features play a role in spatial clumping of vegetation at the study sites, and motivate a study of spatial averaging using TINs.

\section{Triangulated Irregular Networks}

TINs are commonly used to visualize and quantify topography (Peuker and others 1978), and have recently been used to create computationally efficient representations of watershed topography for hydrological models (Ivanov and others 2004; Vivoni and others 2004, 2005a, b; Hancock 2006). TINs are based on Delaunay triangulation, which maximizes the minimum angle of all triangles (that is, avoids creating triangles that are highly obtuse or with a severely acute internal angle) for a given set of nodes. Unique corresponding Voronoi polygons can be created by connecting the perpendicular bisectors of the Delaunay triangles. These Voronoi polygons are investigated as spatial averaging operators here.

We begin our investigation of spatial averaging with TINs by using the topographic convergence index $(\lambda$, Beven and Kirkby 1979) to select node density, following the approach described by Vivoni and others (2005b). Vivoni and others (2005b) argued that TIN node density $\left(d_{\text {nodes }}\right)$ should follow a functional relationship with the topographic feature of interest, that is, $d_{\text {nodes }}$ (or mean node spacing $=f(\lambda)$, to add spatial resolution in areas of higher flow for modeling watershed hydrology. In our case, $\lambda$ roughly follows a gamma distribution at both micro- and macro-scales, and a logical choice of $f(\lambda)$ is a cumulative distribution function of the gamma distribution. Nodes were randomly placed until they reached the density that results in a mean pixel size that represents a range between large and small pixels. We chose 10 bins, similar to the 7 bins chosen in the Vivoni and others (2005b) study. Note that our approach is similar to that described by Figure 3 of Vivoni and others (2005b), but we use the number of nodes per $\lambda$ bin, rather than mean point spacing, as our metric of node density. After creating the TIN, LAI values were determined to be within a particular Voronoi polygon using a point-in-polygon algorithm (MATLAB, Natick, MA, USA).

A neutral case $\left[f(\lambda)_{0}\right]$ was also investigated to test the effects of randomly positioned Voronoi polygons versus TINs conditioned on topographic indices. $f(\lambda)_{0}$ maintains constant $d_{\text {nodes }}$ per topographic index bin, yet uses the same random node placement algorithm and bin size. Due to the random nature of the node placement, a Monte Carlo method with 30 iterations was chosen to quantify the statistics and possible results for each mean pixel size for both $f(\lambda)_{1}$ and $f(\lambda)_{0}$.

After the preliminary study using TINs conditioned on $\lambda$, we explore TINs based on TOPEX. Statistically higher clumping was observed at the micro-scale at low and high TOPEX as quantified by Moran's local indicators of spatial association (LISA) (Anselin 1995; Spadavecchia and others 2008). TOPEX was normally distributed across the micro-scale study domain, so we chose a form of $f$ (TOPEX) based on the normal distribution for this analysis. Namely, $f$ (TOPEX) has low $d_{\text {nodes }}$ at higher and lower TOPEX to create larger Voronoi polygons in areas where the probability of vegetation clumping is greater. The null case $f(\text { TOPEX })_{0}$, similar to $f(\lambda)_{0}$, is also examined.

\section{Digital Elevation Map and Topographic Indices}

A detailed digital elevation map (DEM) with appropriate spatial resolution is required to quantify $\lambda$ and TOPEX. The DEM used for the macroscale analysis was created from airborne LiDAR (light detection and ranging) data collected in July, 2005 using an Optech Airborne Laser Terrain Mapper 3033 (Optech Inc., Vaughan, ON, Canada). The point cloud was gridded on $4 \mathrm{~m}$ grid cells using minimum values of the last pulse data recorded. The DEM used for the micro-scale analysis was 
created using surveying techniques described in the study of van Wijk and Williams (2005).

$\lambda$ is defined as $\ln (\delta / \tan \chi)$ where $\delta$ is the upslope contributing area determined using the flowdirection and flowaccumulation commands standard in ArcGIS and $\chi$ is the local slope (Beven and Kirkby 1979). TOPEX was determined using TOPOSCALE.aml written by Niklaus Zimmerman and available at www.wsl.ch/staff/niklaus.zimmermann/ programs/aml4_l.html.

\section{PLIRTLE Model}

The 'PLIRTLE' ecosystem C flux model of Shaver and others (2007) is used for the analysis of spatial aggregation on upscaled estimates of biogeochemical cycling. PLIRTLE derives its name from its representation of photosynthesis $(\mathrm{P})$ as a function of LAI and irradiation (here photosynthetic proton flux density, PPFD), and of ecosystem respiration $(\mathrm{ER})$ as a function of air temperature $(\mathrm{T})$ and LAI.

The model for $P$ model follows the aggregated canopy photosynthesis model of Rastetter and others (1992). P is assumed to follow a saturating response to PPFD and is integrated through the canopy using the Beer-Lambert law for light attenuation:

$$
P=\left(\frac{P_{\max }}{k} \ln \left(\frac{P_{\max }+E_{o} \mathrm{PPFD}}{P_{\max }+E_{o} \mathrm{PPFD} e^{-k \mathrm{LAI}}}\right)\right),
$$

where $k$ is the light extinction coefficient (assumed here to be 0.5, Shaver and others 2007), $E_{o}$ is the light sensitivity of photosynthesis, and $P_{\max }$ is maximum photosynthesis.

Shaver and others (2007) found that ER models that include two sources-one sensitive to LAI and one not, the latter presumably from deeper soil horizons-fare better than assuming a single substrate pool when modeling chamber-based flux measurements from a pan-Arctic dataset. We use the model 'ER ${ }_{2}^{\prime}$ (Shaver and others 2007):

$$
\mathrm{ER}=\mathrm{LAI} \times R_{0} e^{b T}+R_{x},
$$

where $R_{0}$ is base respiration at $0^{\circ} \mathrm{C}, R_{x}$ is the LAI, $T$ is insensitive component of $\mathrm{ER}$, and $b$ is the temperature sensitivity of ER. We use the parameter set derived for pan-Arctic measurements in both Toolik Lake, AK and Abisko for the $\mathrm{C}$ cycle simulation (Table 1). The choice of the pan-Arctic rather than the local measurement set follows from the findings of Shaver and others (2007), who demonstrated similar PLIRTLE parameter sets across tundra vegetation types in Alaska and Sweden and thus functional convergence in the $\mathrm{C}$ cycle of Arctic tundra.
Table 1. The Pan-Arctic Parameter Set for the PLIRTLE Model with ER Model 2 and Fixed Light Extinction Coefficient $(k)$ after Shaver and others (2007)

\begin{tabular}{lc}
\hline Parameter & Value \\
\hline$P_{\max }$ & $15.831^{1}$ \\
$k$ & 0.5 \\
$E_{0}$ & 0.036 \\
$R_{0}$ & $0.602^{1}$ \\
$b$ & 0.074 \\
$R_{\chi}$ & $0.547^{1}$ \\
${ }^{{ }^{\mu m o l ~} \mathrm{CO}_{2} \mathrm{~m}^{-2} \mathrm{~s}^{-1} .}$ & \\
\hline
\end{tabular}

\section{Meteorological Measurements}

Meteorological measurements for applying PLIRTLE were made on the nearby ABACUS Arctic tundra meteorological tower located at 411,191.84 m east, 7,577,785.175 $\mathrm{m}$ north, $751.907 \mathrm{~m}$ asl. PPFD was measured using an SKP 215 Quantum Sensor (Skye Instruments, Llandrindod Wells, UK) at a height of $2 \mathrm{~m}$. T was measured using a HMP45 sensor (Vaisala, Helsinki, Finland) at a height of $2 \mathrm{~m}$. Periods of missing meteorological data were gapfilled using the linear relationship between PPFD and $T$ data from the meteorological station at the nearby Abisko Scientific Research Station (410,130 m east, 7,583,892 m north [UTM zone $34 \mathrm{~W}$ ], $427.06 \mathrm{~m}$ asl) and the ABACUS Abisko Birch meteorological and eddy covariance tower $(410,615.906 \mathrm{~m}$ east, $7,580,681.110 \mathrm{~m}$ north, $569.950 \mathrm{~m}$ asl). A period from June 9, 2007 to September 22, 2007 that roughly corresponds to the growing season at Abisko was chosen for this analysis.

\section{Results}

Results from the IC analysis on the spatial averaging of LAI with rectangular pixels are presented first, and are then compared with results from the TINs conditioned on topographic features (Vivoni and others 2004, 2005b). The case study on upscaling modeled C flux estimates using IC-preserving and naïve spatial averaging approaches follows in the "Discussion" section.

\section{Rectangular Averaging Operators}

The $E_{\mathrm{S}, \mathrm{n}}$ of spatially averaged LAI changed by not more than 0.07 (7\% of the potential range) at the macro-scale for all rectangular shapes examined at pixel sizes up to $10^{3.9} \mathrm{~m}^{2}$ (Figure $2 \mathrm{~A}$ ); this is the difference in $E_{\mathrm{S}, \mathrm{n}}$ between the LAI data as indicated by the ' $x$, ' and $E_{\mathrm{S}, \mathrm{n}}$ after spatial aggregation of LAI 

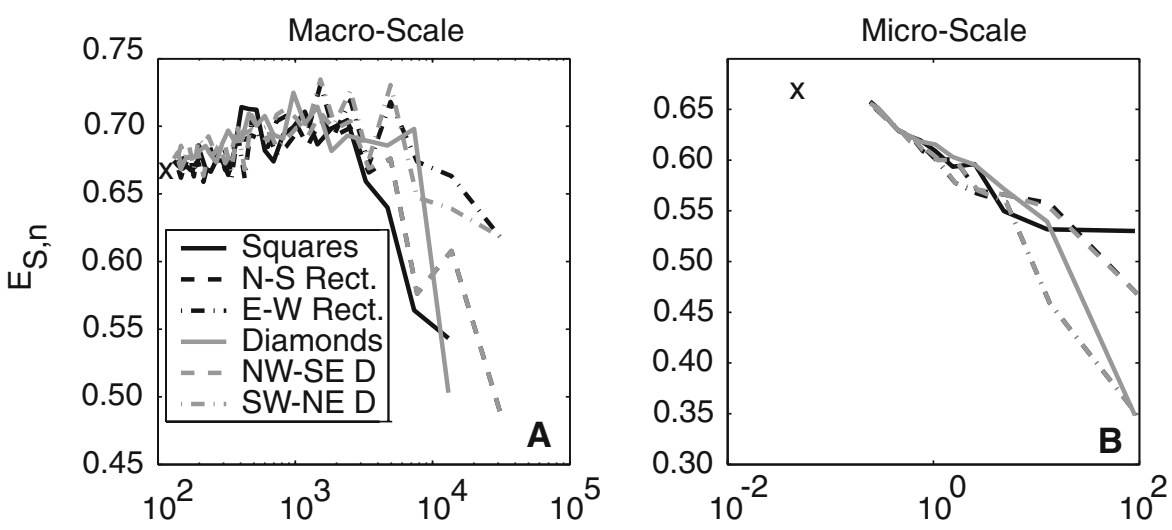

Figure 2. The change in IC upon spatial averaging of LAI using various rectangular shapes and orientations for the macro-scale and micro-scale study areas near Abisko, Sweden. The normalized Shannon entropy $\left(E_{\mathrm{S}, \mathrm{n}}\right)$, numerical Kullback-Leibler divergence $\left(D_{\mathrm{KL}}\right)$ and analytical Kullback-Liebler divergence for the gamma distribution $\left(\Gamma D_{\mathrm{KL}}\right)$ are the IC metrics explored. The $x$ s signify the $E_{\mathrm{S}, \mathrm{n}}, D_{\mathrm{KL}}$, and $\Gamma D_{\mathrm{KL}}$ at the smallest spatial scale of the respective measurements: $85 \mathrm{~m}^{2}$
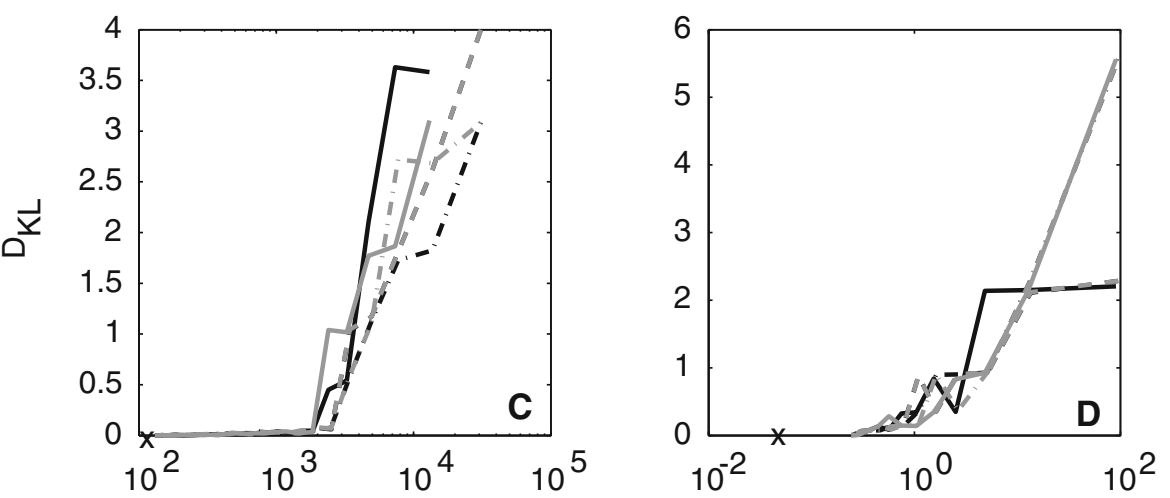
(approximately $10^{2} \mathrm{~m}^{2}$ ) in the case of the coarse scale data and $0.04 \mathrm{~m}^{2}$ for the fine scale data.

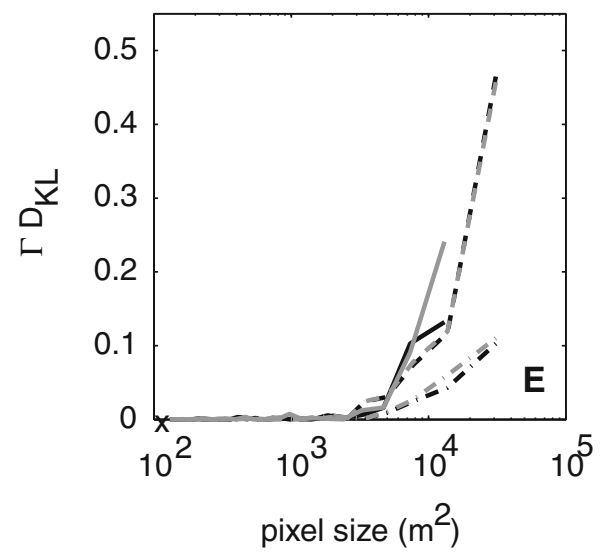

within square pixels. $E_{\mathrm{S}, \mathrm{n}}$ dropped by up to $17 \%$, depending on shape, upon averaging with rectangles larger than $10^{3.9} \mathrm{~m}^{2}$. The $D_{\mathrm{KL}}$ of rectangular pixels increased rapidly from zero at a pixel sizes larger than approximately $10^{3.2} \mathrm{~m}^{2}$ (Figure 2C). The increase in $\Gamma D_{\mathrm{KL}}$ with larger rectangular pixels was not as pronounced (Figure 2E), but occurred at a similar pixel size. Large rectangles with east-west and southwest-northeast orientation, those roughly perpendicular to the stream, retained $E_{\mathrm{S}, \mathrm{n}}$ nearer to fine-scale measurements and returned lower $D_{\mathrm{KL}}$ and $\Gamma D_{\mathrm{KL}}$ than other shapes of the same size.

There was a steady decline in the $E_{\mathrm{S}, \mathrm{n}}$ with increasing pixel size when averaging micro-scale

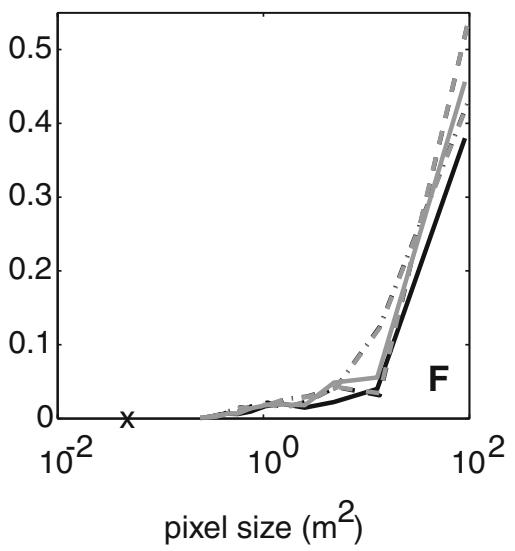

LAI data (Figure 2B). (Pixels smaller than $10^{-1} \mathrm{~m}^{2}$ were not investigated as pixel sizes this small are unlikely candidates for ecological or hydrological studies.) The $E_{\mathrm{S}, \mathrm{n}}$ of square pixels decreased less than other rectangular shapes with increasing pixel size. The $D_{\mathrm{KL}}$ of squares and NW-SE (along stream) rectangles were smaller than other rectangular shapes at the largest pixel size investigated (Figure 2D). The change in $\Gamma D_{\mathrm{KL}}$ for the microscale dataset was roughly equal for all shapes and sizes investigated, but squares had the lowest $\Gamma D_{\mathrm{KL}}$ at the largest pixel size (Figure 2F).

The causes of the alterations in IC (Figure 2) were the changes in $p(\mathrm{LAI})$ after spatial averaging 

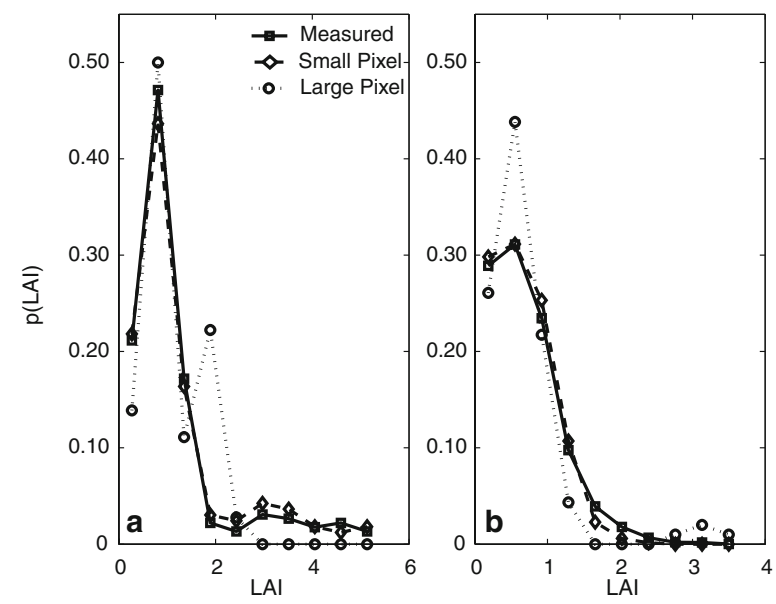

Figure 3. The change in the probability density of LAI after spatial averaging with relatively small and large square pixels for the (A) macro-scale and (B) micro-scale LAI measurements. The small pixels demonstrated here are $1.02 \times 10^{3} \mathrm{~m}^{2}$ at the macro-scale and $0.79 \mathrm{~m}^{2}$ at the microscale. Large pixels are approximately $1.37 \times 10^{4} \mathrm{~m}^{2}$ at the macro-scale and $13.4 \mathrm{~m}^{2}$ at the micro-scale.

demonstrated in Figure 3. Choosing a relatively small pixel size for averaging the macro-scale measurements set resulted in $p$ (LAI) that retained the canonical shape of the data (Figure 3A). In contrast, larger square pixels decreased the $p$ (LAI) in the smallest bin and returned no values for the five largest potential bins; these were averaged out.' An anomalous peak at an LAI near $2 \mathrm{~m}^{2} \mathrm{~m}^{-2}$ is also observed after averaging with large square pixels. This feature is not present in the measurements. The $E_{\mathrm{S}, \mathrm{n}}, D_{\mathrm{KL}}$, and $\Gamma D_{\mathrm{KL}}$ quantify these deviations from the original LAI distribution.

A similar pattern can be observed at the microscale. Choosing relatively small square pixels as averaging operators altered the shape of measured $p$ (LAI) less than larger pixels. $p$ (LAI) decreased in the lowest LAI bin and increased in bin near LAI $=0.5$ (Figure 3B) upon averaging with larger square pixels. $p(\mathrm{LAI})$ increased in LAI bins larger than approximately 2.5 due to the spatial clumping of patches with relatively high LAI (Spadavecchia and others 2008).

\section{Spatial Averaging Using TINs}

TINs conditioned on $\lambda$ outperformed rectangular spatial averaging operators, on average, based on our criteria that large pixels that preserve the $E_{\mathrm{S}, \mathrm{n}}$, $D_{\mathrm{KL}}$, and $\Gamma D_{\mathrm{KL}}$ of measured fine-scale LAI are superior for land surface aggregation (Figure 4). The change in IC incurred by employing square averaging operators frequently exceeded that of any of the 30 iterations of the TIN node placement algorithm with larger mean pixel sizes at the microscale (Figure 4). TINs did not represent an improvement over rectangular pixels for pixel sizes smaller than about $10^{3.4} \mathrm{~m}^{2}$ for the macro-scale data set or approximately $\mathrm{l} \mathrm{m}^{2}$ for the micro-scale dataset. Differences in the IC metrics between $f(\lambda)$ and $f(\lambda)_{0}$ were trivial at both macro-scale and micro-scale.

It was noted by Spadavecchia and others (2008) that TOPEX, rather than $\lambda$, was significantly related to vegetation clumping at the micro-scale; LAI was clumped at both higher and lower TOPEX. TINs with node density based on a normal distribution (lower $\left.d_{\text {nodes }}\right)$ at low and high TOPEX [ $f$ (TOPEX)] were analyzed, along with a null case that did not vary $d_{\text {nodes }}$ by TOPEX bin $\left[f(\text { TOPEX })_{0}\right]$. The $E_{\mathrm{S}, \mathrm{n}}$ and $\Gamma D_{\mathrm{KL}}$ of $f$ (TOPEX) changed less at large mean pixel sizes, on average, than $f$ (TOPEX) $)_{0}$ (Figure 5). $f$ (TOPEX) ${ }_{0}$ showed an increase in $E_{\mathrm{S}, \mathrm{n}}$ across many mean pixel sizes, indicating that $p(\mathrm{LAI})$ was approaching a uniform distribution, which also resulted in the observed increase in $\Gamma D_{\mathrm{KL}}$ (Figure 5). Alterations in the $D_{\mathrm{KL}}$ were nearly identical for $f(\mathrm{TOPEX})_{1}$ and $f(\text { TOPEX })_{0}$ (Figure 5B).

It should be noted that some iterations of the TIN node placement algorithm resulted in IC alterations that were equivalent to or 'worse,' based on the ICpreserving criteria, than rectangular averaging operators for all mean pixel sizes investigated for averaging the macro-scale dataset, and for larger pixel sizes in the micro-scale dataset (Figures 4 and 5). At the same time, all mean pixel sizes investigated included TIN iterations that were 'superior' averaging operators, and the outcome was better than aggregating using square averaging operators more often than not.

\section{Discussion}

\section{Hypothesis 1}

The first hypothesis stated that TINs conditioned on topographic features will be superior averaging operators than rectangular shapes, given our criterion that landscape grids for process-based ecosystem studies should preserve IC and maximize pixel size. We found support for this hypothesis, in most cases, for the ecosystems studied here. Spatial averaging of LAI using TINs better-preserved, on average, the IC of measurements at the macro- and micro-scales. The change in IC incurred by rectangular averaging operators was greater than that of all iterations of the TIN mesh generation algorithm at some mean pixel sizes. On the other hand, some TIN iterations changed IC more than rectangular averaging operators due to the random node 

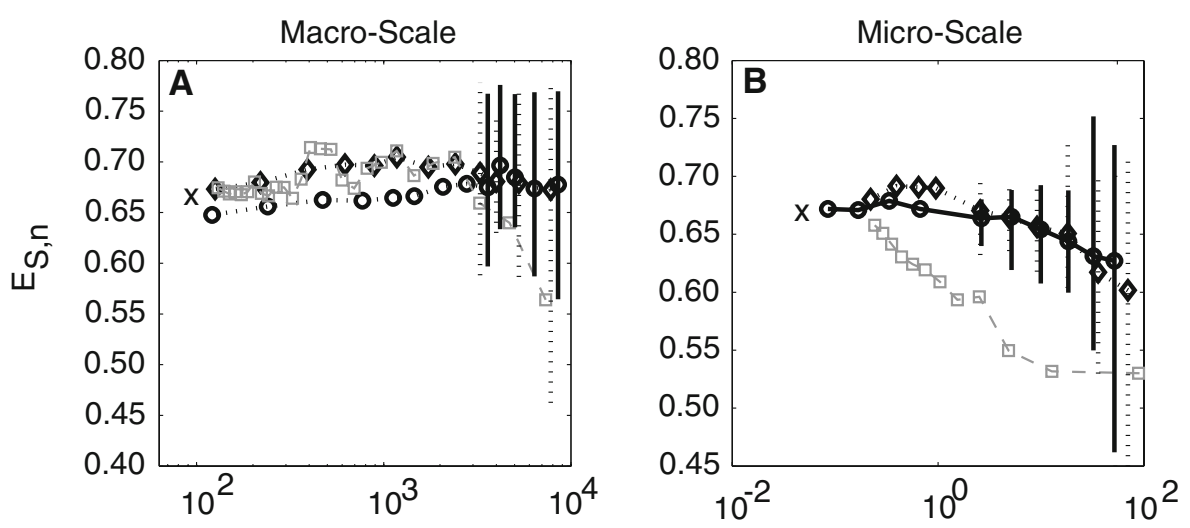

Figure 4. Same as Figure 2, but for spatial averaging using TINs conditioned on topographic convergence index $(\lambda) \cdot f(\lambda)$ uses an increasing gamma distribution of node density as explained in the text. $f\left(\lambda_{0}\right)$ employs a node placement density that does not vary with $\lambda$ bins. 'Square' follows Figure 2 . The TINs were created with random node placement; 30 iterations of the node placement routine were used to explore the variability in normalized
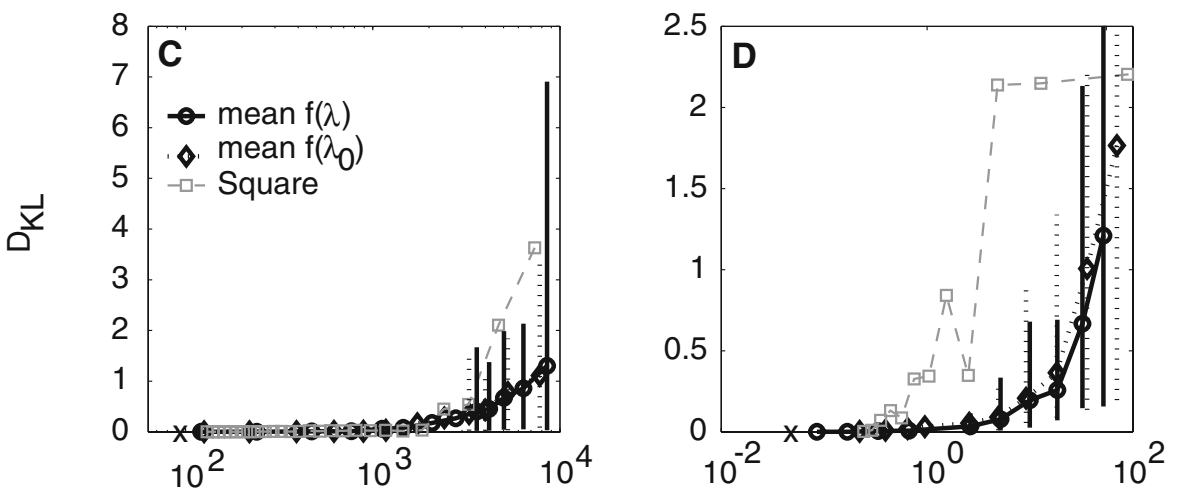

Shannon entropy $\left(E_{\mathrm{S}, \mathrm{n}}\right)$, numerical Kullback-Liebler divergence $\left(D_{\mathrm{KL}}\right)$ and analytical Kullback-Liebler divergence for the gamma distribution $\left(\Gamma D_{\mathrm{KL}}\right)$ incurred by spatial averaging for larger pixel sizes. The vertical bars represent one standard deviation about the mean $E_{\mathrm{S}, \mathrm{n}}$ for the upper panels, and the minimum and maximum of all observed $D_{\mathrm{KL}}$ and $\Gamma D_{\mathrm{KL}}$.
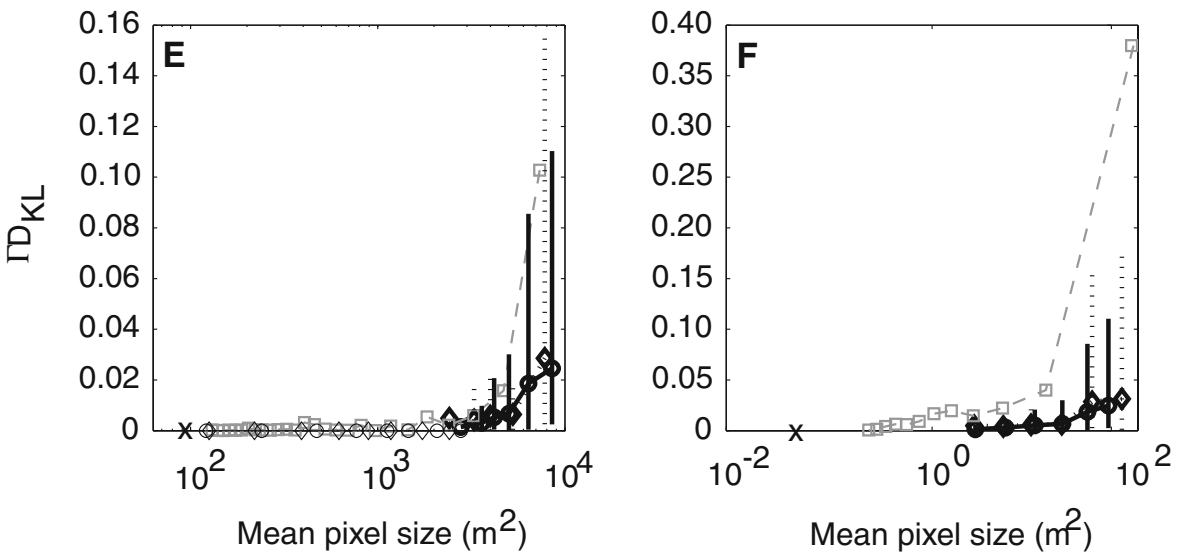

placement algorithm. Any application of TINs for land surface representation that uses random node selection should be carefully analyzed to ensure that the outcome is desirable.

\section{Hypothesis 2}

We hypothesized that TINs conditioned on the landscape features that were most related to LAI clumping, namely TOPEX (Spadavecchia and others 2008), would be superior to TINs based on topographic convergence $(\lambda)$ at the micro-scale. Mean IC after averaging using $f$ (TOPEX) was broadly similar to $f(\lambda)$ and $f(\lambda)_{0}$, with a lower range (Figures 4 and 5), and had lower $\Gamma D_{\mathrm{KL}}$ than $f($ TO$\mathrm{PEX})_{0}$ over much of its range. The largest statistically significant clumps of LAI similarity occurred in the upstream area near the stream and in an exposed micro-plateau to the east of the stream (Spadavecchia and others 2008). Most random TIN iterations did not draw polygons near the edges of these features; hence, hypothesis 2 did not hold due to the random TIN node placement. Nonrandom TIN node placement may represent an improvement for simplifying the spatial patterns that occur across landscapes. 

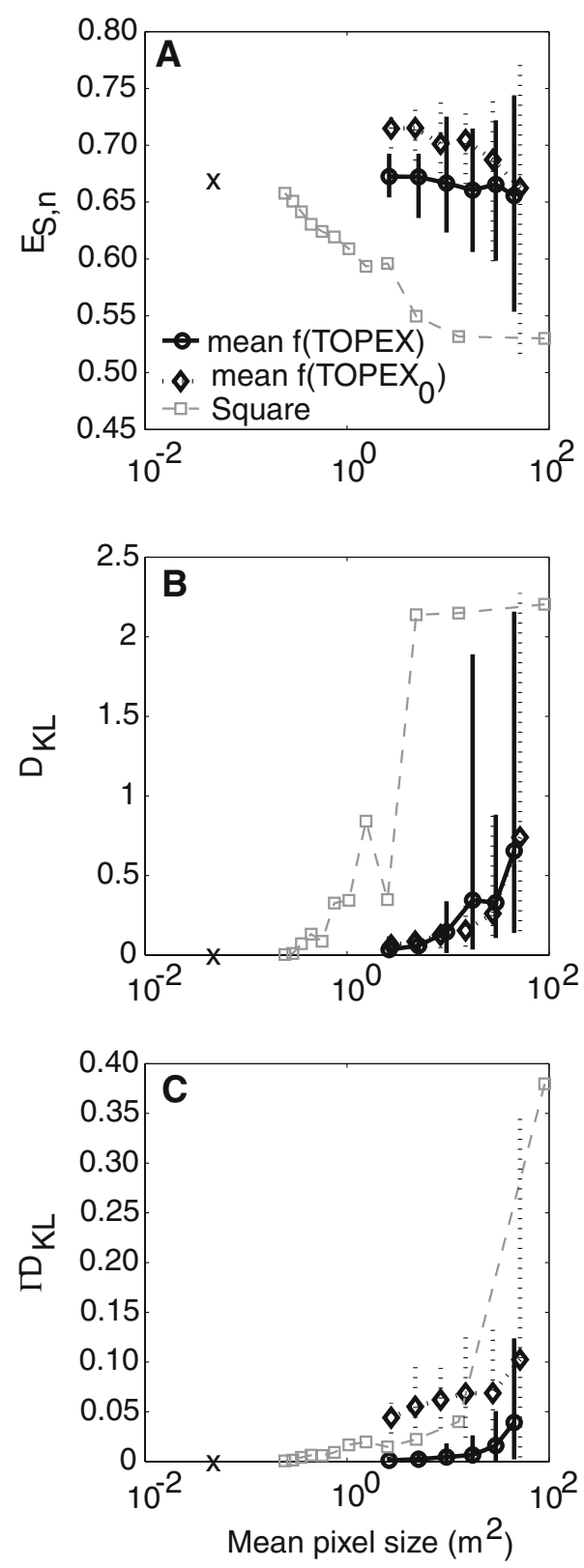

Figure 5. Same as Figure 4, but using TINs conditioned TOPEX for the micro-scale dataset. TOPEX was identified as most significant for LAI clumping as determined Moran's LISA (Spadavecchia and others 2008).

\section{TINs as Averaging Operators}

Are the Voronoi polygons themselves the optimum shape for land surface representation? Not necessarily; highly irregular shapes that correspond more closely to vegetation distribution and/or topography in landscapes with high relief such as the one investigated here may effectively represent the variability in land surface properties with even fewer pixels. The TINs objectively created different sized pixels based on land surface characteristics, which removed the role of the user for pixellating the landscape. Along this line of reasoning, there is no reason why Voronoi polygons could not be combined in cases where adjacent polygons represent similar land surface characteristics to capture the irregular shapes that may describe land surface patches. Such a case is demonstrated by the yellow line in Figure 1B; if there is no discernable advantage to include an edge it can be removed to further decrease the number of pixels used to represent the land surface.

On the same note, If TINs effectively average land surface patches, their edges may provide an estimate of the location and length of edges between vegetation types and/or land surface features. Quantifying 'edge' may be critical for upscaling ecosystem function. For example, lightsaturated photosynthesis in the transition zone between E. hermaphroditum and V. uliginosum patches near the study site was nearly $20 \%$ higher, than photosynthesis in the center of patches dominated by E. hermaphroditum (Fletcher and others unpublished data). Upscaled estimates of photosynthesis in the Abisko landscape may be highly biased if vegetation function at plot edges is not quantified. Edges with narrower or wider areas of influence could be easily incorporated into the Voronoi polygons as demonstrated by the blue bars in Figure 1B. In this way, TINs can be used to preserve the IC of land surface features without ignoring important dynamics of vegetation function such as increased competition at the edges of vegetation patches or other land surface features such as streams or ridges. In addition, concepts from information theory can be applied to ensure that the representation of the land surface for modeling approaches that of the finest grain of observation. To model land surface function at multiple scales, hierarchies of Voronoi polygons may be created to move from individual vegetation patches to larger scales of land surface similarity (Gold and Angel 2006).

The demonstration that TINs based on $\lambda$ have the potential to simplify landscape complexity while preserving IC of vegetation features opens the possibility that TINs for watershed hydrology (Vivoni and others 2004, 2005a) can be coupled to hydrologic models that incorporate vegetation distribution. For example, if the intuitive assumption is made that model patches with greater LAI support more transpiration, TIN-based watershed models for both subsurface and soil-atmosphere water transport can be created. Such models may be used for upscaling ecological and hydrological 
function while minimizing computational load and preserving fine-scale information. An example of such an 'optimal' TIN based on $\lambda$ is presented in Figure $6 \mathrm{~A}$. The $\Gamma D_{\mathrm{KL}}$ of this TIN is $<0.05$, and the mean pixel size is approximately $8500 \mathrm{~m}^{2}$. A comparison of the pdf of the LAI measurements versus TIN-aggregated LAI is presented in Figure 6B. A spatially explicit land surface representation of this sort may help simplify some of the nonlinear impacts of fine-scale patterns in water
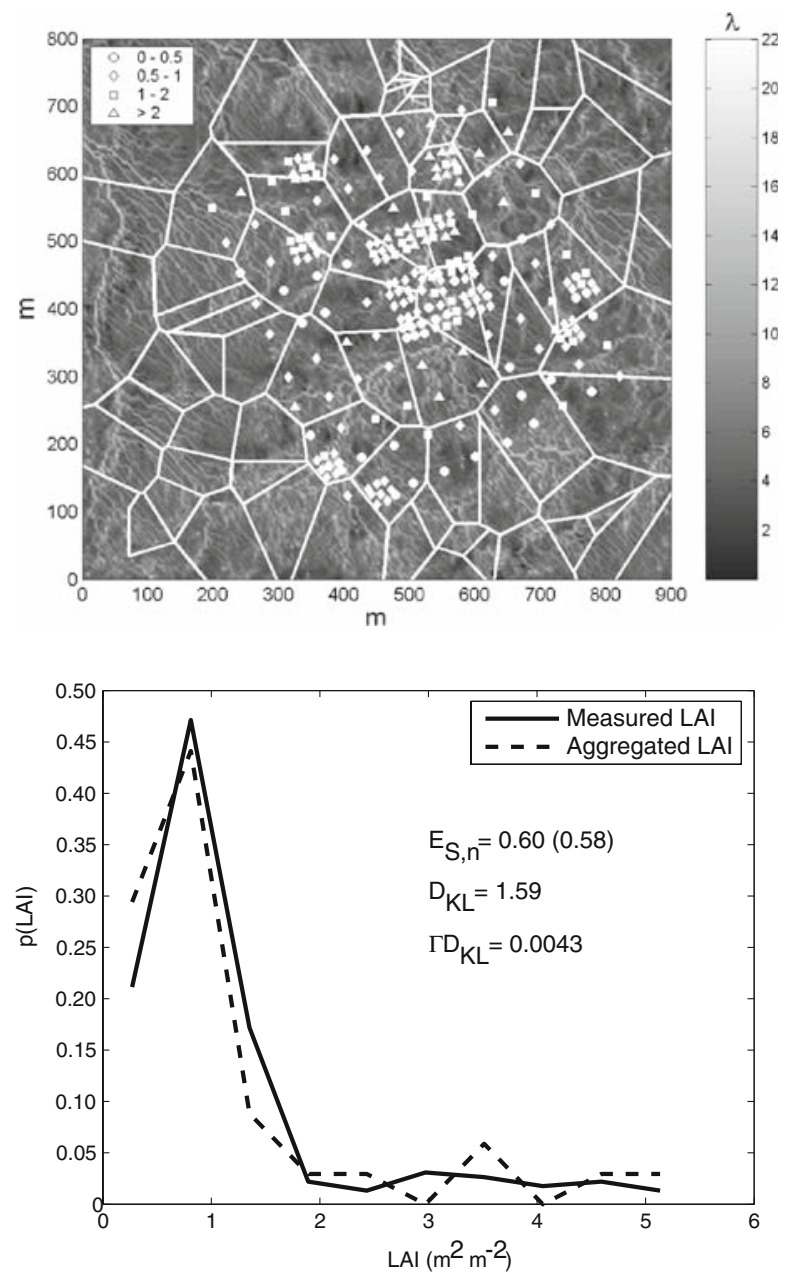

Figure 6. (Top) An example of a TIN for spatial averaging of LAI conditioned on hydrologic similarity via the topographic convergence index, $\lambda$, at the macro-scale (shading, see right-hand side scale). The magnitude and position of measured LAI (Figure 2A) are displayed as white shapes. This TIN is near 'optimal' given the criterion that averaging operators should preserve the IC while maximizing pixel size; the analytical KullbackLiebler divergence for the gamma distribution $\left(\Gamma D_{\mathrm{KL}}\right)$ for this TIN is $<0.005$. The similarity of the measurements and aggregates is also revealed by a comparison of the probability distributions of measured and aggregated LAI (bottom). and radiation fluxes and help address the sub-grid scaling problem (Kustas and Norman 2000; Badiya Roy and Avissar 2002).

\section{Case Study: Upscaling Modeled Landscape-Level C Flux}

In order to demonstrate an application of IC-preservation while upscaling estimates of ecological function, we present an analysis of modeled C flux using the PLIRTLE model for the late growingseason period at Abisko using measured meteorological inputs with measured and aggregated NDVI, and estimated and aggregated LAI. The macro-scale measurements in treeless areas, corresponding to tundra vegetation, were used. NDVI was converted to LAI either before or after the averaging step using the NDVI-LAI transfer function for the Skye NDVI sensor positioned $1.5 \mathrm{~m}$ above ground level (Williams and others 2005):

$$
\mathrm{LAI}=0.00067 e^{9.237 \mathrm{NDVI}} .
$$

NDVI and LAI were considered static in time for this application meant to represent a growing-season period without transient LAI dynamics.

Averaging measured NDVI using large $\left(7335 \mathrm{~m}^{2}\right)$ square pixels resulted in mean LAI estimates that were $11 \%$ smaller $(0.723)$ than LAI estimates from the average of the NDVI measurements, which resulted in modeled NEE $45 \%$ greater (closer to zero) than the estimates that resulted from the NDVI measurements themselves (Table 2). (The micrometeorological convention where flux from atmosphere to biosphere is considered negative is used here.) This is despite the mean of measured and aggregated NDVI being trivially different (ca. $-0.01 \%)$.

In order to alleviate these errors, we created a TIN that preserved the IC of NDVI by iterating through the TIN node selection algorithm until an output in which the $B D_{\mathrm{KL}}$ (equation 4) between measured and averaged NDVI was $<0.005$ was chosen. The mean NDVI and resulting mean LAI between the measured and aggregated approaches was nearly identical, and the difference between NEE estimates from the NDVI measurements and averages was on the order of $1 \%$ (Table 2). This is despite similar mean pixel size between the TIN $\left(7767 \mathrm{~m}^{2}\right)$ and square grid $\left(7335 \mathrm{~m}^{2}\right)$.

Averaging LAI itself using square pixels or optimized TIN outputs resulted in minor differences in model NEE output, on the order of 5 to $8 \%$, because the relationship between LAI and NEE in PLIRTLE is roughly linear over the expected range of LAI in tundra ecosystems (Table 2, Figure 7A), 
Table 2. PLIRTLE (Shaver and others 2007) Model Results for the Net Ecosystem Exchange of C After Spatial Averaging of (Top) Leaf Area Index (LAI) Measurements and (Bottom) NDVI Measurements

\begin{tabular}{lllll}
\hline & Mean NDVI & Mean LAI $\left(\mathrm{m}^{2} \mathrm{~m}^{-2}\right)$ & $\mathrm{NEE}_{\text {mod }}\left(\mathrm{g} \mathrm{C} \mathrm{m}^{-2} \mathrm{~g} \mathrm{~s}^{-1}\right)$ & $\mathrm{NEE}_{\text {pixels }}\left(\mathrm{g} \mathrm{C} \mathrm{m}^{-2} \mathrm{~g} \mathrm{~s}^{-1}\right)$ \\
\hline Averaging LAI & & & & -105.2 \\
$\quad$ Fine-scale & - & 1.20 & -155.2 & $-111.2(-5.70 \%)$ \\
$\quad$ Square pixels & - & $1.08(-10.0 \%)$ & $-128.0(17.5 \%)$ & $-96.5(8.27 \%)$ \\
$\quad$ TIN & - & $1.21(0.00833 \%)$ & $-158.0(-0.0175 \%)$ & -51.1 \\
Averaging NDVI & & 0.814 & -57.2 & $-28.0(45.2)$ \\
$\quad$ Fine-scale & 0.757 & $0.723(-11.2 \%)$ & $-31.4(45.1 \%)$ & $-50.7(0.783 \%)$ \\
$\quad$ Square pixels & $0.749(-.0106 \%)$ & $-56.5(1.24 \%)$ &
\end{tabular}

'Fine-scale' refers to mean model results from all treeless (that is, tundra) measurements in the macro-scale dataset using meteorological inputs for the 2007 growing season. $N E E_{\text {mod }}$ refers to model results after applying the mean of the aggregated LAI values, and NEE $E_{\text {pixels }}$ refers to the mean model result after first applying the model individually to each pixel.

in accordance with recent findings on the roughly linear relationship between LAI and flux in tundra ecosystems (Street and others 2007).

The major difference between the square and ICpreserving upscaling routine began with the slight difference in the distribution of NDVI after averaging in comparison with the measurements (Figure 7B). There were fewer NDVI aggregates in the highest and lowest bins and more in the bin encompassing 0.73; that is, the shape of the NDVI distribution was nearer that of a normal distribution. This change in NDVI distribution propagated to differences in the estimated distribution of LAI (Figure 7C) and consequently NEE (Figure 7D). The importance of accurately averaging NDVI is further shown in Figure 7A, which presents the PLIRTLE-modeled NEE estimates that result from different NDVI and LAI model inputs using the 2007 growing-season meteorological data. PLIRTLE requires an LAI estimate or measurement, but the nonlinearity in the NDVI-LAI conversion can propagate to result in very large differences in modeled NEE (Table 2, Williams and others 2008). Preserving the information contained in the NDVI distribution when applying the NDVI-LAI transfer function is a logical way to upscale NEE estimates with minimal bias.

\section{Future Studies at Abisko}

A major uncertainty for co-classifying ecological/ hydrological/topographic features in the Arctic landscape studied here is the controls on forest patch distribution near the Arctic treeline. Spadavecchia and others (2008) restricted their study to tundra vegetation types given incomplete information on the spatial structure of the treeline. The irregular transition between the forest/wetland matrix and tundra that occurs with elevation at
Abisko must be investigated to accurately model ecological and hydrological processes at this interface. Such modeling efforts should find the balance between simplifying the spatial complexity of the land surface for efficient modeling while accurately characterizing vegetation and surface features.

\section{Future Studies on IC-Based Upscaling}

The particular results of the experimental findings apply to our study site, which is characteristic of tundra ecosystems (Spadavecchia and others 2008). There is no guarantee that conditioning networks based on the topographic indices chosen here will be effective for upscaling ecological function in other ecosystems, but Vivoni and others (2005a) successfully applied their variation of the approach to watersheds with different characteristics. Other likely examples where topographically conditioned TINs may be effective for averaging ecological variability include natural riverine and montane environments where vegetation is clustered around topographic features. Heavily managed landscapes, such as industrial agriculture, may show weaker relationships between topographic indices and vegetation for the application of topographically based TINs. Regardless, upscaling point or plot-scale measurements may benefit from the IC-based approach that we demonstrated for relationships that are nonlinear, including the transfer functions for remotely sensed indices and LAI in agricultural (Haboudane and others 2004) and other global ecosystems (Myeni and others 1997). Choosing an index that has a relationship with LAI that is not so strikingly nonlinear, for example, the enhanced vegetation index may be useful for reducing aggregation errors (Boegh and others 2002), particularly for mixed forest-tundra pixels (Liu and Kafatos 2005). 

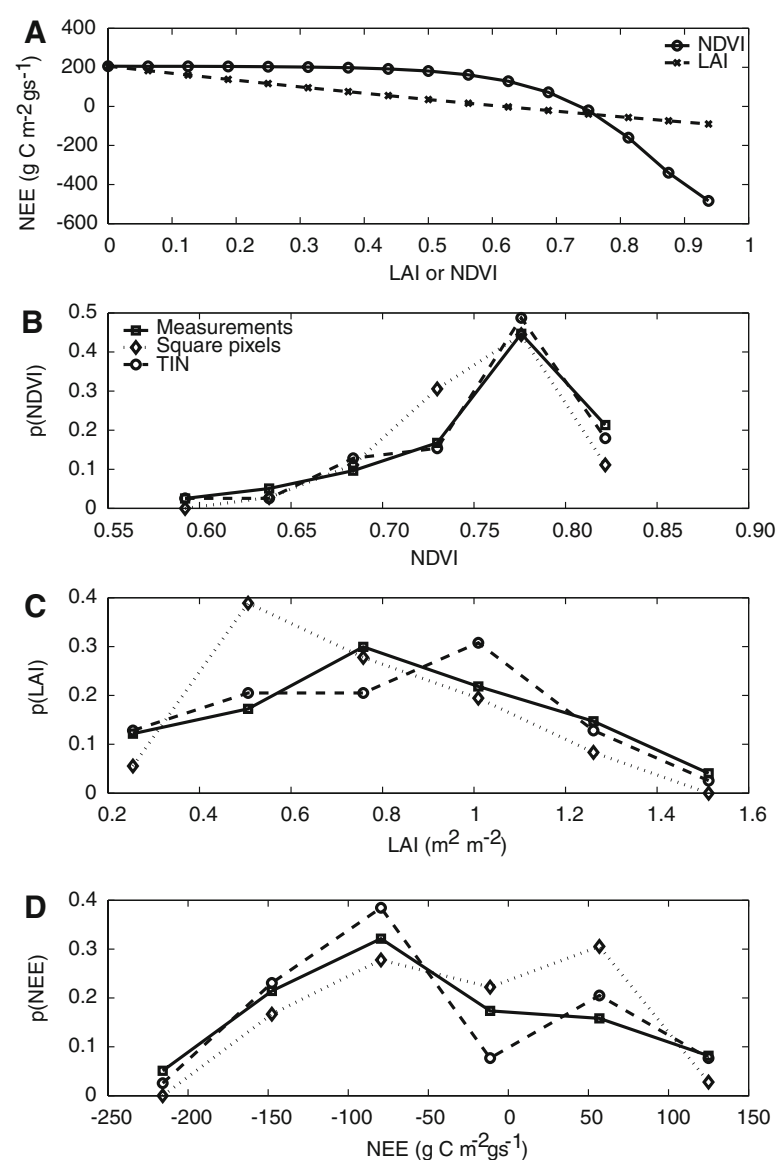

Figure 7. A Modeled net ecosystem exchange of C (NEE) from the PLIRTLE model (Shaver and others 1992) with pan-Arctic parameterization (Table 1) and 2007 growing-season meteorological data for a range of LAI, as well as a range of NDVI that has been converted to LAI using the $1.5 \mathrm{~m}$ NDVI-LAI transfer function described in the study of Williams and others (2008). B The pdf of tundra macro-scale measured NDVI versus NDVI aggregated using square pixels and an optimally designed TIN at a tundra ecosystem near Abisko, Sweden. C The pdf of LAI after conversion from NDVI using the $1.5 \mathrm{~m}$ NDVILAI relationship in the study of Williams and others (2008). D The pdf of modeled net ecosystem exchange of $\mathrm{C}$ (NEE) from the PLIRTLE model.

\section{Information Theory for Upscaling Ecosystem Function}

Concepts from information theory have long been used to describe the distribution of organisms; the Shannon diversity is simply the Shannon entropy for the case of species. Information theory has also been used to characterize mass and energy flows among the networks and trophic levels that characterize ecosystems (Ulanowicz 2001; Jørgensen and others 2007), and provides the theoretical basis for model selection algorithms such as the Akaike information criterion (Akaike 1974). IC has been used less frequently for landscape-level studies (Chen and Blong 2002), research into biogeochemical processes, or land surface modeling, particularly for addressing the 'upscaling' problem (Rastetter and others 1992; Pelgrum 2000). This study represents one example of how simple concepts from information theory can be used for linking plot-level measurements to process-based studies at larger spatial scales, taking the view that 'upscaling' represents the transfer of information between scales in space. This effort is related to previous investigations that sought to minimize within-pixel variance (Band and others 1991) by noting that variance can be defined by the parameters of the distributions used here to define information (for example, variance for the gamma distribution equals $\alpha \beta^{2}$ ). The example with the ecosystem model demonstrated the potential importance of preserving the information contained in the spatial distribution of an ecological characteristic (in this case NDVI) if the model transfer function (to LAI) is nonlinear. Similarly, quantifying information loss or gain when 'downscaling' global and regional models to finer spatial scales may be forthcoming for efficiently quantifying the accuracy of the disaggregation routine. Combining upscaled and downscaled estimates of ecosystem function ultimately rely on the information (in the form of data) that is available, and how these data are combined to present the best estimate of ecosystem function at multiple spatial scales. We envision that IC preservation will be a logical method for reducing errors while extrapolating estimates of ecosystem function to larger scales in space (Brunsell and others 2007, 2008).

\section{ACKNOWLEDGMENTS}

We acknowledge the funding from the US National Science Foundation (Grant numbers OPP-0096523, OPP-0352897, DEB-0087046, and DEB-00895825), from the University of Edinburgh, and from the Natural Environment Research Council. PS, MW, and AP-B were supported by the ABACUS project. LS was supported by a NERC studentship to the Centre for Terrestrial Carbon Dynamics. RB was supported by the University of Edinburgh research funding. Funding for the NERC ARSF flight that carried the ATM sensor used for DEM generation was provided by Bob Baxter and Brian Huntley at the University of Durham. We would like to thank Willem Bouten for use of the LAI-2000, Lorna Street and Sven Rasmussen for field assistance, Ben Poulter for ArcGIS assistance, Terry Callaghan and 
Gus Shaver for general support, and Mathias Disney for valuable comments on the manuscript.

\section{REFERENCES}

Akaike H. 1974. A new look at the statistical model identification. IEEE Trans Automat Contr 19:716-23.

Anselin L. 1995. Local indicators of spatial association-LISA. Geogr Anal 27:93-115.

Badiya Roy S, Avissar R. 2002. Impact of land use/land cover change on regional hydrometeorology in Amazonia. J Geophys Res 107. doi:10.1029/2000JD000266.

Baldocchi DD. 2008. 'Breathing' of the terrestrial biosphere: lessons learned from a global network of carbon dioxide flux measurements systems. Aust J Bot 56:1-26. Turner Review.

Band LE, Peterson DL, Running SW, Coughlan JC, Lammers R. 1991. Forest ecosystem processes at the watershed scale: basis for distributed simulation. Ecol Model 56:171-96.

Beven KJ, Kirkby MJ. 1979. A physically-based variable contributing area model of basin hydrology. Hydrol Sci Bull 24: 43-69.

Bliss LC. 1962. Adaptations of Arctic and alpine plants to environmental conditions. Arctic 15:117-44.

Boegh E, Soegaard H, Broge N, Hasager CB, Jensen NO, Schelde K. 2002. Airborne multispectral data for quantifying leaf area index, nitrogen concentration and photosynthetic efficiency in agriculture. Remote Sens Environ 81:179-93.

Brunsell NA, Ham JM, Owensby CE. 2008. Assessing the multiresolution information content of remotely sensed variables and elevation for evapotranspiration in a tall-grass prairie environment. Remote Sens Environ 112:2977-87.

Brunsell NA, Young CB. 2007. Land surface response to precipitation events using MODIS and NEXRAD data. Int $\mathrm{J}$ Remote Sens 29:1965-82.

Burnham KP, Anderson DR. 2002. Model selection and multimodel inference: a practical information-theoretic approach. New York: Springer, p 488.

Canadell JG, Le Quere C, Raupach MR, Field CB, Buitenhuis ET, Ciais P, Conway TJ, Gillett NP, Houghton RA, Marland G. 2007. Contributions to accelerating atmospheric CO2 growth from economic activity, carbon intensity, and efficiency of natural sinks. Proc Natl Acad Sci U S A 104:18353-4.

Chen K, Blong R. 2002. Integrating remotely sensed images and areal census data for building new models across scales. Geoscience and Remote Sensing Symposium, 2002. IGARSS '02. 2002 IEEE International, vol 4, pp 2385-7.

Christensen TR, Johansson T, Åkerman HJ, Mastepanov M, Malmer N, Friborg T, Crill P, Svensson BH. 2004. Thawing sub-Arctic permafrost: effects on vegetation and methane emissions. Geophys Res Lett 31:L04501.

Entekhabi D, Eagleson PS. 1989. Land surface hydrology parameterization for atmospheric general circulation models including subgrid scale spatial variability. J Clim 2:816-31.

Essery RLH, Best MJ, Betts RA, Cox PM, Taylor CM. 2003. Explicit representation of subgrid heterogeneity in a GCM land-surface scheme. J Hydrometeorol 4:530-43.

Fletcher BJ, Press MC, Baxter R, Phoenix GK. (unpublished data). Plant growth and photosynthesis across transition zones between Arctic vegetation patches: separation of ecological and physiological optima. Funct Ecol.

Gold C, Angel P. 2006. Voronoi hierarchies. In: Raubal M, Miller HJ, Frank AU, Goochild MF, Eds. Geographic information science: 4th international conference, GIScience 2006. Münster, Germany: Springer. p 419.

Goodrich DC, Woolhiser DA, Keefer TO. 1991. Kinematic routing using finite elements on a triangular irregular network. Water Resour Res 38. doi:10.1029/2001WR000854.

Gurney KR, Law RM, Denning AS, Rayner PJ, Pak BC, Baker D, Bousquet P, Bruhwiler L, Chen Y-H, Ciais P, Fung IY, Heimann M, John J. 2004. Transcom 3 inversion intercomparison: model mean results for the estimation of seasonal carbon sources and sinks. Global Biogeochem Cycles 18:GB1010.1011-8.

Haboudane D, Miller JR, Pattey E, Zerco-Tejada PJ, Strachan IB. 2004. Hyperspectral vegetation indices and novel algorithms for predicting green LAI of crop canopies: modeling and validation in the context of precision agriculture. Remote Sens Environ 90:337-52.

Hancock GR. 2006. The impact of different gridding methods on catchment geomorphology and soil erosion over long timescales using a landscape evolution model. Earth Surf Processes Landforms 31:1035-50.

Heinsch FA, Zhao M, Running SW, Kimball JS, Nemani RR, Davis KJ, Bolstad PV, Cook BD, Desai AR, Ricciuto DM, Law BE, Oechel WC, Kwon H, Luo H, Wofsy SC, Dunn AL, Munger JW, Baldocchi DD, Xu L, Hollinger DY, Richardson AD, Stoy PC, Siqueira MBS, Monson RK, Burns S, Flanagan LB. 2006. Evaluation of remote sensing based terrestrial productivity from MODIS using AmeriFlux tower eddy flux network observations. IEEE Trans Geosci Remote Sens 44: 1908-25.

Ivanov VY, Vivoni ER, Bras RL, Entekhabi D. 2004. Catchment hydrologic response with a fully distributed triangulated irregular network model. Water Resour Res 40:W11102. doi:11110.11029/12004WR003218.

Jarvis PG, McNaughton KG. 1986. Stomatal control of transpiration: scaling up from leaf to region. Adv Ecol Res 15:1-49.

Jonasson S, Michelsen A, Schmidt IK, Nielsen EV. 1999. Responses in microbes and plants to changed temperature, nutrient and light regimes in the Arctic. Ecology 80:1828-43.

Jørgensen SE, Marques JC, Müller F, Nielsen SN, Patten PC, Tiezzi E, Ulanowicz RE. 2007. A new ecology: systems perspective. Amsterdam: Elsevier, p 275.

Katul GG, Lai C-T, Albertson JD, Vidakovic B, Schäfer KVR, Hsieh CI, Oren R. 2001. Quantifying the complexity in mapping energy inputs and hydrologic state variables into landsurface fluxes. Geophys Res Lett 28:3305-7.

Kullback S. 1997. Information theory and statistics. Mineola, NY: Dover Publications, p 416.

Kullback S, Leibler RA. 1951. On information and sufficiency. Ann Math Stat 22:79-86.

Kumler MP. 1994. An intensive comparison of triangulated irregular networks (TINs) and digital elevation models (DEMs). Cartographica 31: Monograph 45, 41-48.

Kustas WP, Norman JM. 2000. Evaluating the effects of subpixel heterogeneity on pixel average fluxes. Remote Sens Environ 74:327-42.

Leuning R, Kelliher FM, DePury DG, Schulze E-D. 1995. Leaf nitrogen, photosynthesis, conductance and transpiration: scaling from leaves to canopies. Plant Cell Environ 18:1183200.

Liu X, Kafatos M. 2005. Land-cover mixing and spectral vegetation indices. Int J Remote Sens 26:3321-7.

Mathiassen JR, Skavhaug A, Bø K. 2002. Texture similarity measure using Kullback-Leibler divergence between gamma 
distributions. Computer Vision-ECCV 2002. Berlin: Springer, p 19-49.

Mauser W, Tenhunen JD, Schneider K, Ludwig R, Stolz R, Geyer R, Falge EM. 2001. Remote sensing, GIS and modelling: assessing spatially distributed water, carbon and nutriend balances in the Ammer River catchment, in southern Bavaria. In: Tenhunen JD, Lenz R, Hantschel R, Hunter S, Eds. Ecosystem approaches to landscape management in central Europe. Berlin: Springer.

Monteith JL, Unsworth MH. 1990. Principles of environmental physics. London: Edward Arnold, p 291.

Müller C, Lucht W. 2007. Robustness of terrestrial carbon and water cycle simulations against variations in spatial resolution. $\mathrm{J}$ Geophys Res 112:D06105. doi:06110.01029/02006JD007875.

Myeni RB, Nemani RR, Running SW. 1997. Estimation of global leaf area index and absorbed PAR using radiative transfer models. IEEE Trans Geosci Remote Sens 35:1380-93.

O'Neill RV, Rust B. 1979. Aggregation error in ecological models. Ecol Model 7:91-105.

Pelgrum H. 2000. Aggregation of a nonlinear land surface model for heterogeneous terrain. Remote sensing and hydrology. Santa Fe, NM: IAHS.

Peuker TK, Fowler RJ, Little JJ, Mark DM. 1978. The triangulated irregular network. Proceedings of the DTM symposium. American Society of Photogrammetry-American Congress on Surveying and Mapping. Saint Lois, MO. pp 24-31.

Potter CS, Klooster SA, Nemani R, Genovese V, Hiatt S, Fladeland M, Gross P. 2006. Estimating carbon budgets for U.S. ecosystems. EOS Trans Am Geophys Union 87:85-96.

Quaife T, Lewis P, de Kauwe M, Williams M, Law BE, Disney M, Bowyer P. 2008. Assimilating canopy reflectance data into an ecosystem model with an ensemble Kalman filter. Remote Sens Environ 112:1347-64.

Rahman AF, Gamon JA, Sims DA, Schmidts M. 2003. Optimum pixel size for hyperspectral studies of ecosystem function in southern California chaparral and grassland. Remote Sens Environ 84:192-207.

Rastetter EB, King AW, Cosby BJ, Hornberger GM, O'Neill RV, Hobbie JE. 1992. Aggregating fine-scale ecological knowledge to model coarser-scale attributes of ecosystems. Ecol Appl 2: 55-70.

Shannon CE. 1948. A mathematical theory of communication. Bell Syst Tech J 27:379-423. 623-56.

Shaver GR, Billings WD, Chapin FS, Giblin AE, Nadelhoffer KJ, Oechel WC, Rastetter EB. 1992. Global change and the carbon balance of Arctic ecosystems. Bioscience 42:433-41.

Shaver GR, Chapin FS, Gartner BL. 1986. Factors limiting growth and biomass accumulation in Eriophorum vaginatum L. in Alaskan tussock tundra. J Ecol 74:257-78.

Shaver GR, Street LE, Rastetter EB, van Wijk MT, Williams M. 2007. Functional convergence in regulation of net $\mathrm{CO}_{2}$ flux in heterogeneous tundra landscapes in Alaska and Sweden. J Ecol 95:802-17.

Spadavecchia L, Williams M, Bell R, Stoy PC, Huntley B, van Wijk MT. 2008. Topographic controls on the leaf area index of a Fennoscandian tundra ecosystem. J Ecol doi:10.1111/ j.1365-2745.2008.01424.x.

Stoy PC, Katul GG, Siqueira MBS, Juang J-Y, Novick KA, Oren R. 2006. An evaluation of methods for partitioning eddy covariance-measured net ecosystem exchange into photosynthesis and respiration. Agric For Meteorol 141:2-18.

Street LE, Shaver GR, Williams M, van Wijk MT. 2007. What is the relationship between changes in canopy leaf area and changes in photosynthetic CO2 flux in Arctic ecosystems? J Ecol 95:139-50.

Sullivan PF, Arens SJT, Chimner RA, Welker JM. 2008. Temperature and microtopography interact to control carbon cycling in a high Arctic fen. Ecosystems 1 1:61-76.

Tenhunen JD, Geyer R, Valentini R, Mauser W, Cernusca A. 1999. Ecosystem studies, land-use change, and resource management. In: Tenhunen J, Kabat P, Eds. Integrating hydrology, ecosystem dynamics, and biogeochemistry in complex landscapes. West Sussex: Wiley. p 1-19.

Ulanowicz RE. 2001. Information theory in ecology. Comput Chem 25:393-9.

van Wijk MT, Williams M. 2005. Optical instruments for measuring leaf area index in low vegetation: application in Arctic ecosystems. Ecol Appl 15:1462-70.

van Wijk MT, Williams M, Shaver GR. 2005. Tight coupling between leaf area index and foliage $\mathrm{N}$ content in Arctic plant communities. Oecologia 142:421-7.

Vivoni ER, Ivanov VY, Bras RL, Entekhabi D. 2004. Generation of triangulated irregular networks based on hydrological similarity. J Hydrol Eng 9:288-302.

Vivoni ER, Ivanov VY, Bras RL, Entekhabi D. 2005. On the effects of triangulated terrain resolution on distributed hydrologic model response. Hydrol Processes 19:2101-22.

Vivoni ER, Teles V, Ivanov VY, Bras RL, Entekhabi D. 2005. Embedding landscape processes into triangulated terrain models. Int J Geogr Inf Sci 19:429-57.

Walker DA, Auerbach NA, Lewis BE, Shippert MM. 1995. NDVI, biomass, and landscape evolution of glaciated terrain in northern Alaska. Polar Rec 31:169-78.

Walko RL, Avissar R. 2006. The ocean-land-atmosphere model (OLAM): a new generation of earth system model. EOS Trans. AGU 87 Fall Meeting Suppl., Abstract A33F-05.

Wesson KH, Katul GG, Siqueira MBS. 2003. Quantifying organization of atmospheric turbulent eddy motion using nonlinear time series analysis. Bound-Layer Meteorol 106: 507-25.

Wilby RL, Wigley TML. 1997. Downscaling general circulation model output: a review of methods and limitations. Prog Phys Geogr 21:530-48.

Williams M, Bell R, Spadavecchia L, Street LE, van Wijk MT. 2008. Upscaling leaf area index in an Arctic landscape through multi-scale observations. Glob Chang Biol 14. doi:10.1111/ j.1365-2486.2008.01590.x.

Williams M, Rastetter EB. 1999. Vegetation characteristics and primary productivity along an Arctic transect: implications for scaling-up. J Ecol 87:885-98.

Williams M, Rastetter EB, Shaver GR, Hobbie JE, Carpino E, Kwiatkowski BL. 2001. Primary production of an Arctic watershed: an uncertainty analysis. Ecol Appl 11:1800-16.

Williams M, Schwarz PA, Law B, Irvine J, Kurpius MR. 2005. An improved analysis of forest carbon dynamics using data assimilation. Glob Chang Biol 11:89-105. 